\title{
To Engage Business Students, Roll Out 'the Barrels'
}

\author{
Whitney Peake (Western Kentucky University) \\ Teran Sundy (Western Kentucky University)
}

KEYWORDS: Management, Leadership, Teaching Methods, Strategy, Family Business.

Many of us may remember the "Choose Your Own Adventure" books from childhood. In these tales, the story develops to a point and presents a scenario choice to the reader. Depending on the choice made by the reader, the storyline develops with different events, sequences and outcomes.

The purpose of this exercise is to provide a platform for students to use their creativity in a family business management course as they infuse their own concept knowledge and ideas into a "choose your own adventure" story a fictional family in the bourbon industry: "the Barrels." It will require only minimal materials, which allows professors to integrate it at any point in the semester and have students apply the case to a number of family business management concepts with only a short prompt. The best responses from students can then be used for additional exam and case prompts. The professor and students jointly develop the case throughout the semester by introducing different events and outcomes based on the best, most interesting, and/or most surprising takes on the case. This exercise has been successfully used with undergraduate students.

\section{Introduction}

Kentucky has a long history in bourbon production, creating multi-generation family business dynasties as the industry continues to flourish. As one of the state's most important industries, bourbon generates $\$ 3$ billion in revenues and employs over 15,000 people. The Brown family of Brown-Forman has produced bourbon since 1870 and the seventh generation of Beams currently oversee Jim Beam and Heaven Hill distilleries. Given the current market interest in bourbon, and the rich history of multi-generation family businesses, this fictional "choose your own adventure" case allows students to examine a family business within the context of a dynamic, family business-centered industry.

\begin{abstract}
The fictitious Barrel family case can be integrated into the course and extended at any point in the semester. I launched the case in mid-September, and integrated it into in-class activities, two assignments and all three exams for the course.
\end{abstract}

\section{Advance Preparation}

Students should be provided with bourbon industry resources (see the links at the end of this article) and Barrel family information (from the exhibits below) early in the semester. I also provide an IBISWorld "Whiskey \& Bourbon Distilleries" industry report PDF to students via our course systems platform, since Western Kentucky University has access to this service; however, ample industry reports and resources are available online if your university does not have access to IBISWorld.

\section{The Exercise}

I introduced the Barrel Family information and initial exercise to the students after covering theories related to family businesses, family culture and family systems, family harmony, planning, challenges associated with ownership and management, and professionalization in family firms.

To launch the exercise, I introduced the Barrel Family Genogram, Bourbon Barrel Brands organizational structure, and what we know about the Barrel family slides in approximately 15 minutes at the beginning of class. To get students comfortable with thinking and writing about the fictional company, I gave them the inclass assignment detailed in Exhibit 1. Students were given 45 minutes to create responses to the five questions in teams of 3-4 students. We then took the remaining 15 minutes of class to discuss their responses to the questions presented during the inclass exercise. This exercise served as an exam review, since some of these questions could be selected for the first exam. In addition to the introductory exercise, we used the Barrel family case to illustrate concepts at

Copyright @ 2017 The Authors. Entrepreneur \& Innovation Exchange is published at EIX.org. This is an open access article under the terms of the Creative Commons Attribution-NoDerivs License, which permits use and distribution in any medium, provided the original work is properly cited and 
each class meeting.

\section{Discussion}

This fictional "choose your own adventure" case allows students the opportunity to more creatively apply their knowledge of basic family business management issues throughout the course. Students writing the case extensions are proud to see their work highlighted in future assignments, gaining additional buy-in from the class. With minimal case parameters, both the instructor and students have the opportunity to build the case to meet class-specific needs. Instructors can take the case in any direction they need, to highlight or illustrate a point, with characters that make such extensions quite easy and time efficient. Students enjoy further developing the family characters, identifying with them and crafting additional stories to examine course concepts.

The exhibits below highlight how the family information was leveraged for further case development. Note that the Poza (2010) textbook was used for this course, although the case could be adapted to match any general family business textbook presentation.

\section{Exhibit 1: In-Class Introduction Exercise}

The following questions were part of the introductory inclass exercise.

Using the Barrel Family information presented in class, provide responses to these questions on family business concepts.

1. Woodford Barrel used company product to supply a personal party. Use agency theory to explain the problem here.

2. Explain the three-generation rule. How does this apply to the Barrel family?

3. What are three considerations the Barrel family should include when creating a family employment policy?

4. Explain how the Barrel family might experience difficulty with the belief that fair means equal in family governance and how they may overcome this difficulty.

5. Based on the Barrel family, what are 2-3 key principles that should be included in the family constitution? Why?

\section{Exhibit 2: Example Barrel Case Prompts for first exam}

The following questions were included on the first exam as a warm-up and tie-in to course concepts about theories related to family business, family culture and family systems, family harmony, planning, challenges of ownership and management, and professionalization (corresponds to Poza (2010) Chapters 1-4).

1. Woodford Barrel used company product to supply a personal party. Use agency theory to explain these actions and the problem with doing this. What are two things the family could do to avoid these problems in the future?

2. Explain how the Barrel family might experience difficulty with the belief that fair means equal in family governance. Provide 2 - 3 recommendations related to how they may overcome this difficulty.

\section{Exhibit 3: Example Barrel Case Extension Prompt}

The following prompt and questions were used as an assignment for the class related to the concept of strategic fit, strategic fit in the family business and succession (corresponds to Poza (2010), Chapters 5 and 6).

Please answer the questions below. You may write the case in any way you want, and make any assumptions that you want - as long as you are true to the basic assumptions provided in the original Barrel family documents. The best continuation (or pieces of continuation) will be used to craft more of the case.

1. The Barrel family has decided that a strategysetting session is needed to move the business forward. How do they start? Where should they start? Who should participate?

2. How should the Barrel family prepare the upcoming generations? Who should be involved? Who appears best suited? Why?

3. Integrate how Pappy Barrel could be expected to handle succession into your responses.

\section{Exhibit 4: Example Barrel Case Extension Prompt}

The prompt below (written by a student), in conjunction with the questions, was used as an assignment. The 
questions to consider deal with change and innovation in family businesses (corresponds to Poza (2010), Chapter 8).

\section{Prompt}

Bill aka "Pappy," and Marge Barrel launched the distillery company Barrel Bourbon after they married in 1970. They created a household name for themselves in the bourbon industry and consistently seek ways to move the company to the next level. Bill and Marge have three children: Jim, Woodford and Rose. Each of the three children are heavily involved in the company and they all anticipate their father's choice to assume leadership of the company. Rose serves as the company's Chief Financial Officer, Jim as the Director of Production, and Woodford as the Director of Sales.

Pappy, while serving as the president of the company, began to experience extreme health issues. Marge recognized it was time for him to take a step back, and Pappy knew he had to make swift decisions in order for the business to move along smoothly after he left. It was always his wish that his eldest son Jim would take over the company and that Woodford would later succeed him. Although he cherished his beloved daughter Rose and her outstanding contributions as Chief Financial Officer to the company, he always felt protective of her and never wanted her to take on the stressful and demanding role of president.

Anxious about his company and concerned about his health and children, Pappy decided to organize a family meeting. He informed Jim, Woodford and Rose of his concerns and what he wished for the business going forward. He told them he was considering Jim to succeed him as president and explained why. With tensions flaring among the siblings, he was unable to control his children's emotions and thought at that moment it would have been best had he taken a different approach to his idea for succession.

Unfortunately, this would be Pappy's last meeting with his children, as later that evening he passed away. With Pappy gone and the state of the company in an uproar, Jim immediately began to carry out his duties as president even though no formal vote was held. Rose and Woodford questioned their positions in the company and the future positions of the upcoming generations, as neither sibling was prepared for their father's sudden death.
Rose and Woodford are completely devastated and cannot seem to get along amicably with Jim at this time. Jim has now completely shifted his focus toward the company and his father's last wishes and feels he is the one deserving to lead the company going forward. Although the company is profitable, the divide is not going unnoticed by stakeholders (employees, customers, etc.)

\section{Questions to Consider}

1. How can Jim move forward to get "buy in" as the leader of the company? Are there ways he can help change the culture without damaging past successes?

2. Is there anything that Jim should not do as he steps up as leader of the firm?

3. What best practices related to family business management and transition should Jim start to implement, to ensure Barrel Brands is successful for the generations to come?

\section{Exhibit 5: Example Case Prompt and Exam Questions}

This case extension was written by a student, and was utilized in the second exam, along with the questions that follow. The questions related to strategic fit, grooming the next generation, transfer of power, and innovation in family firms (corresponds to Poza (2010), chapters 5,6,7, and 8).

Marge Barrel started to notice something different about Pappy. He seemed reclusive after his days at work, preferring to sip bourbon alone in his study into the wee hours of the night before coming to bed. Knowing Pappy's ways, Marge had a feeling about what was going on. After about a week of this behavior, Marge confronted Pappy in his study. After a few drinks, Pappy explained to Marge that he is beginning to realize that he will not be able to run the business forever. It was time to discuss the future of Barrel Bourbon after Pappy steps down.

Marge knew that Pappy was likely to take his sweet time in this process, paralyzed out of uncertainty and his love and concern for the family and the business. Marge took it upon herself to start these discussions, visiting Jim, Woodford and Rose on her own time. She listened to how each of her children about their future in the business. She learned that while Woodford would love 
the social ramifications of being the leader of a successful business, he was not responsible enough with the family's assets to be an effective CEO. Rose, already the CFO, was very knowledgeable about the business's activities. She saw the need for succession a few years ago, but was afraid to mention it to Pappy. Jim, the current GM of Production, felt a little uncomfortable talking about the future of the business without Pappy around, and swiftly left to go to work. McKenna, Jim's wife, was left alone with Marge, and took the opportunity to tell her that Jim does see himself taking Pappy's place one day, but has not said anything because he is afraid to step on his father's toes.

Ruing the lack of communication between her children and their father, Marge held a family dinner, inviting all the board members to her house to discuss succession over lasagna. Barton Brand, Rose's husband and the family's attorney, led the conversation. He told the family he is ready to help Pappy and Marge prepare wills and revamp the business's shareholder agreements to best fit the future ownership structure. Jack Danielson, the family accountant, spoke up, saying it would be a good idea to evaluate and prepare for the kind of estate transfer tax the business faces. At these prompts, the children began to share their ideas for a succession plan, but never addressed their desires to take over the business. Pappy remained quiet and seemingly resigned, listening to the conversation with a poker face.

After this meeting, it was clear to Marge and the rest of the family that outsiders proved to be more helpful in catalyzing change than family members. Marge then researched various business and leadership consultants in the area and contacted the best one. She discussed the cost of this consultation with the accountant, and Jack told her it would be well worth it. Marge pitched this idea to Pappy, and he agreed, trusting that his wife has done her research (and preferring to stay out of the major decisions for now).

Marge, Pappy, Rose, Barton, Jim, McKenna, Woodford, Jack and the consultant, Kathy, are now involved in the succession planning process. Kathy agreed to check in with the Barrel family once a month for two years, moderating Board meetings and directing the Barrel family toward important decisions. In the past year, it has been decided that Rose and Jim are the main candidates for the position of CEO. Rose appears to be suited for the job because of her tacit knowledge of the business's financial affairs and because she worked most closely with Pappy day-to-day. Jim, however, has the trust of the entire production force, and knows the business's operations well. They appear an even match for the position of CEO.

\section{Potential Exam Questions}

1. Imagine that you are Rose in this situation. Create four scenarios of statements from Rose that illustrate each type of commitment: affective commitment, normative commitment, calculative commitment and imperative commitment. Briefly defend which type of commitment seems to best "fit" Rose's situation given the case information and extension.

2. Think across the situations shared for the Barrel family both in the original case and in the case extension. Suppose that as part of the consultation with Kathy, the family will be undertaking some strategic planning initiatives over the next year. Given the summary sheet of the strategic fit model (12S model), what major segment [(1) Strategy, (2) Structure, (3) Shareholder, or (4) Succession, Staff, Skills \& Social Capital] of the business needs to be addressed first in the strategy-setting session? Why?

3. Based on the case and case extension, discuss (1) which CEO exit type you believe would be most likely to be undertaken by Pappy, and (2) which CEO exit type you believe would be least likely to be undertaken by Pappy. Provide justification.

4. Suppose that Rose is selected as the next CEO. Discuss three leadership traps that Rose should avoid, and describe how she might avoid or overcome them.

5. In their meetings with the consultant, the Barrel family appears to be undertaking which type of decision-making approach (i.e., autocratic, democratic, collaborative/consensus)? Is this generally a good approach for a family business? Why or why not?

\section{Exhibit 6: Example Exam Questions}

The following questions related to the Barrel family case were used on the third exam, related to family governance, strategic planning, estate planning and crafting co-owners' plans (corresponds to Poza (2010) chapters 9,10,11, and 12). 
1. The Barrel family has decided to choose a new board and have consulted you for help. What would you tell them are the most important factors to consider when choosing board members? Explain how the Barrel family should utilize these factors to make wise decisions in selecting their board of directors.

2. Based on the Barrel family information, conduct a SWOT analysis for Barrel Brands. How can they leverage their strengths and opportunities to create a competitive advantage? What is their primary source of competitive advantage?

(Note: feel free to make any assumptions here that you need to do this as long as you justify them).

\title{
Links
}

Fortune Article on Bourbon Industry (http://fortune.com/2014/02/06/the-billion-dollarbourbon-boom/)

Kentucky Bourbon Tales: Distilling the Family Business (KET Video)
Brown Family
Forbes
Ranking
(http://www.forbes.com/profile/brown/)

\author{
Bourbon Family Dynasties - Bourbon Heritage \\ Center \\ (http://www.bourbonheritagecenter.com/history/th \\ e-family-and-key-players/)
}

Statement on Passing of Parker Beam (http://kybourbon.com/kda-statement-regardingpassing-parker-beam/)

\section{More ideas}

College business professors looking for more ideas to enrich the classroom experience can find them here (https://familybusiness.org/eix-in-class) .

Additional Search Terms: entrepreneurship courses, teaching ideas, teaching resources, classroom ideas, entrepreneurship classes, business schools, business school classes, entrepreneurship students, professors 